\title{
Faecal shedding, alimentary clearance and intestinal spread of prions in hamsters fed with scrapie
}

\author{
Dominique KRÜGER ${ }^{1 \ddagger}$, Achim ThOMZIG $^{1 \ddagger}$, Gudrun LENZ $^{1 \ddagger}$, Kristin KAMPF $^{1}$, \\ Patricia MCBRIDE ${ }^{2}$, Michael BEEKES ${ }^{1 *}$ \\ ${ }^{1}$ Robert Koch-Institute, P24-Transmissible Spongiform Encephalopathies, Nordufer 20, \\ D-13353 Berlin, Germany \\ ${ }^{2}$ Institute for Animal Health, Neuropathogenesis Unit, West Mains Road, Edinburgh EH9 3JF, United Kingdom
}

(Received 1 November 2007; accepted 29 September 2008)

\begin{abstract}
Shedding of prions via faeces may be involved in the transmission of contagious prion diseases. Here, we fed hamsters $10 \mathrm{mg}$ of $263 \mathrm{~K}$ scrapie brain homogenate and examined the faecal excretion of disease-associated prion protein $\left(\mathrm{PrP}^{\mathrm{TSE}}\right)$ during the course of infection. The intestinal fate of ingested $\mathrm{PrP}^{\mathrm{TSE}}$ was further investigated by monitoring the deposition of the protein in components of the gut wall using immunohistochemistry and paraffin-embedded tissue (PET) blotting. Western blotting of faecal extracts showed shedding of $\operatorname{PrP}^{\mathrm{TSE}}$ in the excrement at $24-72 \mathrm{~h}$ post infection (hpi), but not at $0-24 \mathrm{hpi}$ or at later preclinical or clinical time points. About $5 \%$ of the ingested $\operatorname{PrP}^{\mathrm{TSE}}$ were excreted via the faeces. However, the bulk of $\mathrm{PrP}^{\mathrm{TSE}}$ was cleared from the alimentary canal, most probably by degradation, while an indiscernible proportion of the inoculum triggered intestinal infection. Components of the gut-associated lymphoid tissue (GALT) and the enteric nervous system (ENS) showed progressing accumulation of PrP ${ }^{\text {TSE }}$ from 30 days post infection (dpi) and $60 \mathrm{dpi}$, respectively. At the clinical stage of disease, substantial deposits of PrP ${ }^{\mathrm{TSE}}$ were found in the GALT in close vicinity to the intestinal lumen. Despite an apparent possibility of shedding from Peyer's patches that may involve the follicle-associated epithelium (FAE), only small amounts of $\mathrm{PrP}^{\mathrm{TSE}}$ were detected in faeces from clinically infected animals by serial protein misfolding cyclic amplification (sPMCA). Although excrement may thus provide a vehicle for the release of endogenously formed $\mathrm{PrP}^{\mathrm{TSE}}$, intestinal clearance mechanisms seem to partially counteract such a mode of prion dissemination.
\end{abstract}

prion / oral infection / Peyer's patches / enteric nervous system / faeces

\section{INTRODUCTION}

Transmissible spongiform encephalopathies (TSE), also termed prion diseases [1], such as scrapie in sheep and goats, bovine spongiform encephalopathy (BSE), chronic wasting disease (CWD) of elk and deer, or human Creutzfeldt-Jakob disease (CJD) and its variant form vCJD are neurodegenerative and ultimately fatal diseases of the central nervous system (CNS). Characteristically, TSE

\footnotetext{
* Corresponding author: BeekesM@ rki.de

$\ddagger$ Authors contributed equally.
}

are associated with the deposition in the brain and spinal cord of a pathological form of the prion protein $(\mathrm{PrP})$ with an abnormally altered folding and/or aggregation structure. The prion hypothesis holds that the causative and transmissible agents of TSE consist in proteinaceous infectious particles ("prions") that are composed essentially - if not entirely - of misfolded $\mathrm{PrP}$, designated as $\operatorname{PrP}^{\mathrm{Sc}}[36,37]$. Disease-associated prion protein, in the following referred to as $\operatorname{PrP}^{\mathrm{TSE}}[8,13]$, can be detected in samples from affected animals or humans by analytical methods such as 


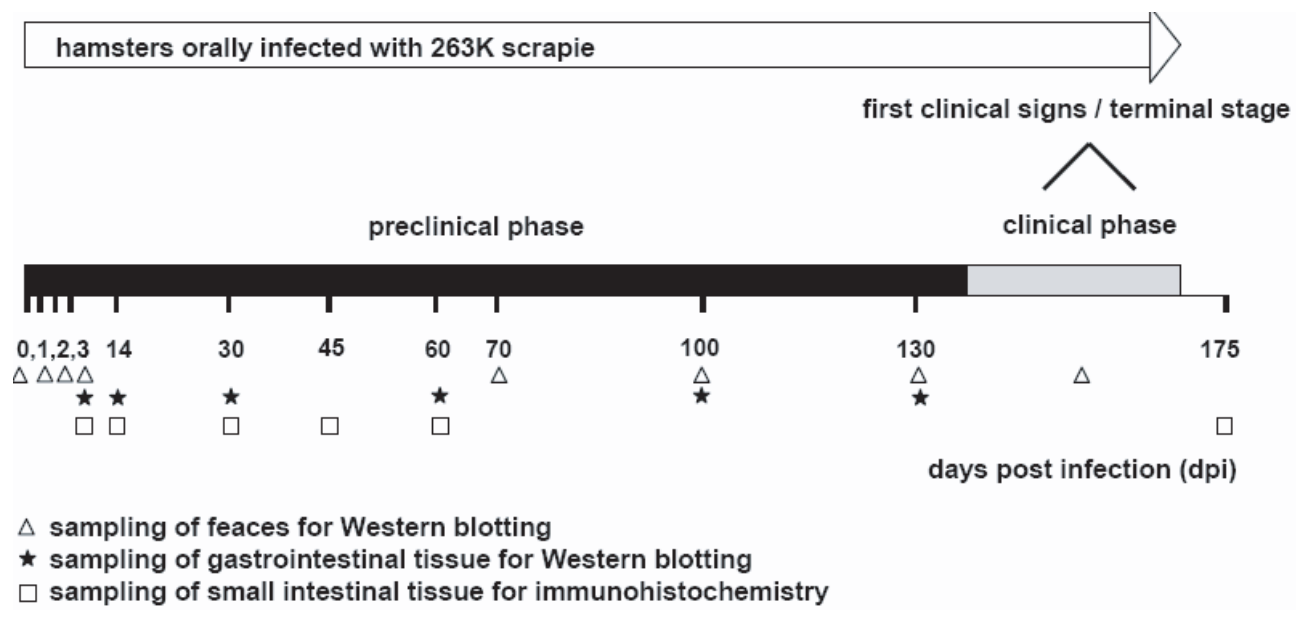

Figure 1. Time scale displaying the preclinical and clinical phases of incubation of hamsters orally infected with $263 \mathrm{~K}$ scrapie and indicating the time points at which samples from the animals were collected and tested for PrP $\mathrm{PSE}^{\mathrm{TSE}}$. Faeces samples collected at $0-24,24-48,48-72$ and $72-96$ hpi were referred to in the figure as specimens from $0,1,2$, and 3 dpi, respectively.

immunohistochemistry (IHC) [22, 33, 47], Western blotting [5, 40, 52], or paraffinembedded tissue (PET) blotting [41].

In naturally acquired scrapie, CWD, BSE, and $\mathrm{VCJD}$, infection seems to occur most often by ingestion of TSE agents and subsequent invasion of the host via the alimentary tract $[8$, 28]. Scrapie of sheep and goats and CWD of cervids are contagious diseases that are transmitted horizontally in the field. Contaminated placenta, decomposed carcasses, saliva, urine or skin have been suggested as the contagion of these diseases $[15,30,34,38,42,46]$, but faeces provide a further candidate vehicle for the release of prions into the environment [29,39].

In the past, hamsters orally challenged with scrapie have been established as a relevant rodent model to study the intestinal pathophysiology of alimentary prion infections by taking advantage of $\operatorname{PrP}^{\mathrm{TSE}}$ as a biochemical marker for infectious prions [7, 8, 33].

Here, we used the hamster model of oral scrapie infection in an attempt to further elucidate pathophysiological events in the intestinal tract following ingestion of prions. In this context, special attention was given to the intestinal fate of ingested $\operatorname{PrP}^{\mathrm{TSE}}$, the course of $\operatorname{PrP}^{\mathrm{TSE}}$ accumulation in the GALT and the ENS, and the shedding of $\operatorname{PrP}^{\mathrm{TSE}}$ in faeces.

\section{MATERIALS AND METHODS}

\subsection{Animal inoculation}

All animal experiments were performed using outbred Syrian hamsters. The studies in animals complied with German legal regulations and were approved by the responsible review boards. Hamsters were fed food pellets doused each with $100 \mu \mathrm{L}$ of a $10 \%$ (w/v) hamster-brain homogenate derived from terminally ill donors infected with $263 \mathrm{~K}$ scrapie agent, and control animals were mock challenged with brain homogenate from normal hamsters as described previously [3].

\subsection{Biochemical detection of $\operatorname{PrP}^{\mathrm{TSE}}$ in faeces}

For sampling of faeces, hamsters were placed in metabolic cages (Harvard Apparatus, Holliston, USA) with free access to food and drinking water. Animals were transferred into metabolic cages once they had ingested the infectious inoculum, and faecal samples were collected at 0-24hpi, 24$48 \mathrm{hpi}, 48-72 \mathrm{hpi}, 72-96 \mathrm{hpi}$, at 70, 100, and $130 \mathrm{dpi}$ prior to the onset of scrapie symptoms, and when the animals were in advanced clinical stages of the disease between 145 and 160 dpi (see Fig. 1). 
Faeces from individual animals $(n \geq 8$ for each investigated time point) sampled before they were perorally challenged with scrapie agent served as negative controls.

A $10 \%(w / v)$ faecal homogenate, adjusted with normal hamster brain homogenate as carrier material to a final concentration of $0.125 \%(\mathrm{w} / \mathrm{v})$ brain tissue, was prepared with an ultraturrax in TBS buffer $(50 \mathrm{mM}$ Tris/ $\mathrm{HCl}, 150 \mathrm{mM} \mathrm{NaCl}$, $\mathrm{pH}$ 7.2). Extraction of $\operatorname{PrP}^{\mathrm{TSE}}$ from the faecal homogenate was performed by using a previously published protocol [4] with modifications. In brief: A total of $2 \mathrm{~mL}$ sample homogenate (containing $200 \mathrm{mg}$ of faeces) was distributed equally on two $1.5 \mathrm{~mL}$ centrifuge vials. All centrifugations were performed in a TLA-55 rotor (Beckman). Samples were centrifuged at $5000 \mathrm{rpm}(1500 \times g)$ and $4{ }^{\circ} \mathrm{C}$ for $3 \mathrm{~min}$, the supernatants were collected and the pellets resuspended in $0.5 \mathrm{~mL}$ TBS each. These suspensions were submitted to a second centrifugation at $5000 \mathrm{rpm}\left(1500 \times \mathrm{g}, 4^{\circ} \mathrm{C}, 3 \mathrm{~min}\right)$, and the resulting supernatants were collected and mixed with the supernatants from the previous centrifugation and centrifuged again for $40 \mathrm{~min}$ at $20000 \mathrm{rpm}(25000 \times g)$ and $4{ }^{\circ} \mathrm{C}$.

The resulting pellets were resuspended in $600 \mu \mathrm{L} 1 \%(\mathrm{w} / \mathrm{v})$ sarcosyl in TBS using an ultrasonic probe and centrifuged for $40 \mathrm{~min}$ at $20^{\circ} \mathrm{C}$ and $20000 \mathrm{rpm}(25000 \times \mathrm{g})$. The resulting supernatants were pooled and submitted to a further centrifugation at $45000 \mathrm{rpm}(125000 \times \mathrm{g})$ and $4{ }^{\circ} \mathrm{C}$ for $2.5 \mathrm{~h}$. The resulting pellet was resuspended in $1 \mathrm{~mL} 0.1 \%$ sarcosyl in TBS, homogenized by ultrasonification, and incubated with constant shaking at $37^{\circ} \mathrm{C}$ in the presence of $12.5 \mu \mathrm{g} / \mathrm{mL}$ proteinase $\mathrm{K}(\mathrm{PK})$ for $15 \mathrm{~min}$. After a final centrifugation for $2.5 \mathrm{~h}$ at $45000 \mathrm{rpm}(125000 \times g)$ and $4{ }^{\circ} \mathrm{C}$, the resulting pellet was suspended in $20 \mu \mathrm{L}$ of $2 \times$ Laemmli sample buffer, boiled for $5 \mathrm{~min}$ and stored at $-80^{\circ} \mathrm{C}$ until further processing. The final pellet contained $\operatorname{PrP}^{\mathrm{TSE}}$ in the form of its PK-resistant core PrP27-30, which was visualized by Western blotting using CDP-Star solution as described elsewhere [44].

A subset of faecal samples from clinically-ill scrapie hamsters was subjected to serial protein misfolding cyclic amplification (sPMCA) for detection of $\operatorname{PrP}^{\mathrm{TSE}}$. Here, extraction of $\operatorname{PrP}^{\mathrm{TSE}}$ was performed as described above with the following modifications: Treatment with PK was omitted during the extraction, and the resulting pellet of the final centrifugation $(2.5 \mathrm{~h}$ at $45000 \mathrm{rpm}$ and $\left.4{ }^{\circ} \mathrm{C}\right)$ was resuspended directly in $10 \%(\mathrm{w} / \mathrm{v})$ normal brain homogenate in PMCA conversion buffer (phosphate buffered saline containing complete protease inhibitor cocktail by BoehringerIngelheim, Mannheim, Germany, $4 \mathrm{mM}$ EDTA and $1 \%$ Triton-X-100). Serial PMCA was performed as described recently [43].

Faecal samples spiked with $263 \mathrm{~K}$ scrapie hamster brain homogenate served as positive controls and were used to assess the detection limit of our assay. If not otherwise stated, samples representing $200 \mathrm{mg}$ of faeces in the starting homogenates were loaded onto gels for Western blotting of unknown and control faecal specimens.

In order to visualize the immunological crossreactivity of crude faecal material $100 \mathrm{mg}$ of normal hamster faeces were homogenized in $400 \mu \mathrm{L} 2 \times$ Laemmli sample buffer, boiled for $10 \mathrm{~min}$ and centrifuged at $13000 \mathrm{rpm}$ (13000 $\times g$ ). Ten microliters of the resulting supernatant (representing $2 \mathrm{mg}$ of faeces in the starting homogenate) were then loaded onto the gel for $\mathrm{mAb}$ 3F4 Western blotting.

\subsection{Western blot analysis of gastrointestinal tissue for PrP ${ }^{T S E}$}

For Western blot analyses of gastrointestinal tissue samples, hamsters $(n \geq 3$ animals for each examined time point) were sacrificed by $\mathrm{CO}_{2}$ asphyxiation at 3,14,30,60,100, and $130 \mathrm{dpi}$ (see Fig. 1). The entire small intestine was removed, carefully processed to eliminate residual content, and subdivided into 20 segments of about $2 \mathrm{~cm}$ in length weighing between 50 and $100 \mathrm{mg}$. The tissue samples were frozen immediately in liquid nitrogen and stored at $-80^{\circ} \mathrm{C}$ until further processing. After digestion by collagenase and further tissue disintegration by ultrasonification, $\mathrm{PrP}^{\mathrm{TSE}}$ was extracted in the form of PrP27-30 as described elsewhere [4]. Samples from the small intestine of parallel mock-infected hamsters served as negative controls; samples from uninfected hamsters spiked with $263 \mathrm{~K}$ scrapie hamster brain homogenate containing $10^{-6} \mathrm{~g}$ of scrapie brain tissue were used as positive controls (not shown).

At $60,70,80,100$, and $130 \mathrm{dpi}(n=1,1,1$, 2 , and 4 hamsters, respectively) caeca and large intestines as well as the stomachs and oesophagi were removed from sacrificed animals. These tissue specimens, after removal of residual content, were dissected into pieces of between 50 and $100 \mathrm{mg}$ 
A

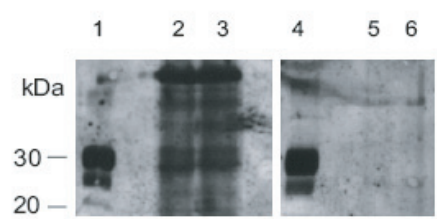

B

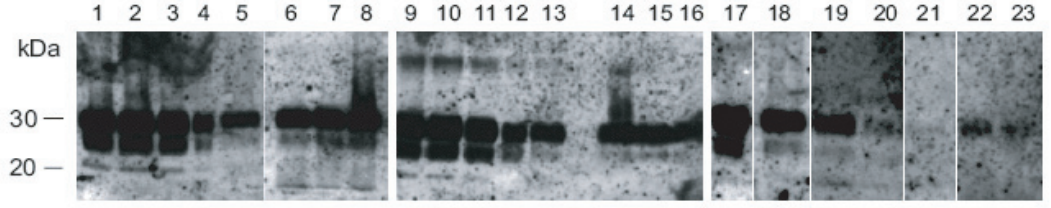

C

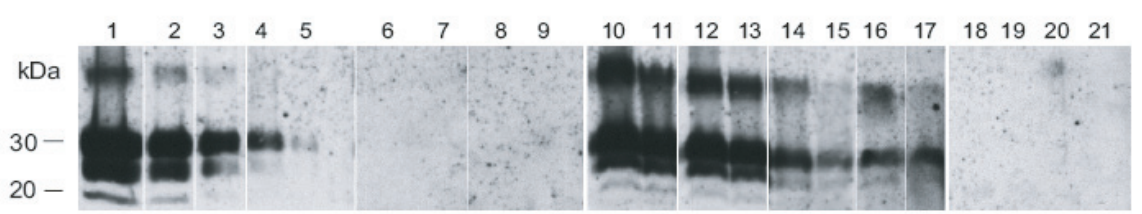

D

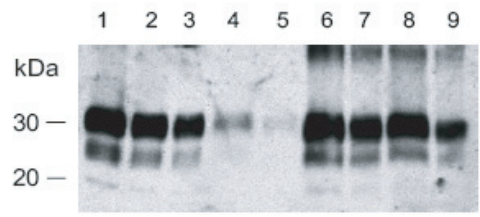

E

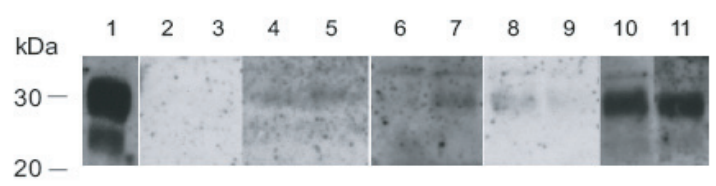

Figure 2. (A) Immunological cross-reactivity of hamster faeces in the Western blot (labeling with mAb 3F4). Lanes 1 and 4: PK digested $263 \mathrm{~K}$ scrapie hamster brain homogenate containing $5 \times 10^{-7} \mathrm{~g}$ of brain tissue. Lanes 2 and 3: Crude homogenates from $2 \mathrm{mg}$ of normal hamster faeces. Lanes 5 and 6 : Purified extracts from $100 \mathrm{mg}$ of normal hamster faeces. (B) Semi-quantitative Western blot assessment of the extraction recovery of PrP27-30, the PK-resistant core of PrP ${ }^{\mathrm{TSE}}$, from hamster faeces spiked with 263K scrapie brain homogenate. Lanes 1-5, 9-13 and 17-21: Serially diluted 263K scrapie hamster brain homogenate containing $1 \times 10^{-6} \mathrm{~g}$ (lanes 1 and 9), $7 \times 10^{-7} \mathrm{~g}$ (lanes 2 and 10 ), $5 \times 10^{-7} \mathrm{~g}$ (lanes 3 and 11 ), $2.5 \times 10^{-7} \mathrm{~g}$ (lanes 4,12 and 17), $1 \times 10^{-7} \mathrm{~g}$ (lanes 5, 13 and 18), $5 \times 10^{-8} \mathrm{~g}$ (lane 19), $2 \times 10^{-8} \mathrm{~g}$ (lane 20) and $1 \times 10^{-8} \mathrm{~g}$ (lane 21) tissue. Lanes 6-8: Extracts from $200 \mathrm{mg}$ normal hamster faeces spiked with $5 \times 10^{-6} \mathrm{~g}$ of homogenized $263 \mathrm{~K}$ scrapie brain tissue before purification. Lanes 14-16: Extracts from

Page 4 of 17 (page number not for citation purpose) 
and subjected to extraction and Western blotting of PrP27-30. Negative and positive controls were prepared as described above.

\subsection{Immunohistochemistry and PET blotting for $\operatorname{PrP}^{\mathrm{TSE}}$ detection in intestinal samples}

For immunohistochemical detection of intestinal $\operatorname{PrP}^{\mathrm{TSE}}$ deposition in situ, hamsters were transcardially perfused with periodate lysine paraformaldehyde (PLP) [31] immediately after $\mathrm{CO}_{2}$ euthanasia performed at $3 \mathrm{dpi}(n=2)$, and 14 , 30,45 and $60 \mathrm{dpi}$ ( $n=6$ for each time point), or at the terminal stage of clinical scrapie $(n=3)$ (see Fig. 1). The distal half of the small intestine was removed and subdivided into 10 segments of about $2 \mathrm{~cm}$ in length. Segments from mock-infected animals served as negative controls while terminally ill animals provided intestinal specimens for positive controls. After washing in TBS and postfixation for $5 \mathrm{~h}$ in PLP, the samples were dehydrated in ethanol and embedded in paraffin-wax. For microscopic investigation, $6 \mu \mathrm{m}$ microtome sections were treated with formic acid and immunostained using the monoclonal antibody (mAb) 3F4 [27] and diaminobenzidine as described elsewhere [32]. Normal mouse serum replaced $\mathrm{mAb} 3 \mathrm{~F} 4$ in adjacent sections as the internal control for staining specificity. Additionally, $6 \mu \mathrm{m}$ microtome slices were mounted onto nitrocellulose membranes and processed for
$\operatorname{PrP}^{\mathrm{TSE}}$ detection by PET blotting as described previously $[41,45]$.

The time scale in Figure 1 displays the preclinical and clinical phases of incubation of hamsters orally infected with $263 \mathrm{~K}$ scrapie (see also [46]), and indicates the time points at which samples from the animals were tested for $\mathrm{PrP}^{\mathrm{TSE}}$.

\section{RESULTS}

\subsection{Western blot detection of $\operatorname{PrP}^{\mathrm{TSE}}$ in faeces}

\subsubsection{Specificity, sensitivity and yield of the extraction method}

The monoclonal antibody 3F4 has long since been established as an exquisite immunological probe for Western blot detection of normal and pathological prion protein of hamsters. However, as shown in Figure 2A (lanes 2 and 3), direct PrP analysis of raw hamster faeces by Western blotting is not feasible due to substantial unspecific cross-reactivity with various stool components.

Our protocol for the extraction of $\operatorname{PrP}^{\mathrm{TSE}}$ from faeces removed such interfering components (Fig. 2A, lanes 5 and 6) and reliably allowed detection of PrP27-30 in positive control samples of $200 \mathrm{mg}$ faeces spiked with $5 \times 10^{-7} \mathrm{~g}$ of homogenized $263 \mathrm{~K}$ scrapie

Figure 2 (continued). $200 \mathrm{mg}$ normal hamster faeces spiked with $3 \times 10^{-6} \mathrm{~g}$ of homogenized $263 \mathrm{~K}$ scrapie brain tissue before purification. Lanes 22-23: Extracts from $200 \mathrm{mg}$ normal hamster faeces spiked with $5 \times 10^{-7} \mathrm{~g}$ of homogenized $263 \mathrm{~K}$ scrapie brain tissue before purification. (C) Western blot detection of PrP27-30, the PK-resistant core of PrP ${ }^{\mathrm{TSE}}$, in faeces of hamsters fed with $263 \mathrm{~K}$ scrapie brain homogenate. Lanes 1-5: Serially diluted $263 \mathrm{~K}$ scrapie hamster brain homogenate containing $5 \times 10^{-6} \mathrm{~g}$ (lane 1), $1 \times 10^{-6} \mathrm{~g}$ (lane 2), $2.5 \times 10^{-7} \mathrm{~g}$ (lane 3), $1 \times 10^{-7} \mathrm{~g}$ (lane 4) and $2.5 \times 10^{-8} \mathrm{~g}$ (lane 5) tissue. Lanes 6-21: Extracts from $200 \mathrm{mg}$ faeces sampled at 0-24 hpi (lanes 6-9), 24-48 hpi (lanes 10-13), 48-72 hpi (lanes 14-17) and 72-96 hpi (lanes 18-21) from 4 different animals. (D) Western blot detection of PrP2730 , the PK-resistant core of $\mathrm{PrP}^{\mathrm{TSE}}$, in faeces of hamsters fed with $263 \mathrm{~K}$ scrapie brain homogenate Adjustment of dilutions for semi-quantitative assessment of $\operatorname{PrP}^{\mathrm{TSE}}$ excretion. Lanes 1-5: Serially diluted 263K scrapie hamster brain homogenate containing $5 \times 10^{-7} \mathrm{~g}$ (lane 1), $2.5 \times 10^{-7} \mathrm{~g}$ (lane 2), $1 \times 10^{-7} \mathrm{~g}$ (lane 3), $5 \times 10^{-8} \mathrm{~g}$ (lane 4) and $2 \times 10^{-8} \mathrm{~g}$ (lane 5) tissue. Lanes 6-9: 1:2 (lanes 6 and 8) and 1:5 (lanes 7 and 9) diluted extracts from $200 \mathrm{mg}$ faeces sampled at $24-48 \mathrm{hpi}$ (dilutions were prepared from the extracts represented in lanes 10 and 12 of Fig. 2C). (E) Western blot detection of PrP27-30, the PK-resistant core of $\mathrm{PrP}^{\mathrm{TSE}}$, after serial protein misfolding cyclic amplification (sPMCA) of $\mathrm{PrP}^{\mathrm{TSE}}$ in faeces extracts from clinically diseased scrapie hamsters fed with $263 \mathrm{~K}$ scrapie agent. Lane 1: $263 \mathrm{~K}$ scrapie hamster brain homogenate containing $5 \times 10^{-7} \mathrm{~g}$ tissue. Lanes 2-11: sample signals of extracts from $200 \mathrm{mg}$ faeces of two donor animals after 200 (lanes 2 and 3), 250 (lanes 4 and 5), 300 (lanes 6 and 7), 350 (lanes 8 and 9) and 400 (lanes 10 and 11) cycles of sPMCA. 
A

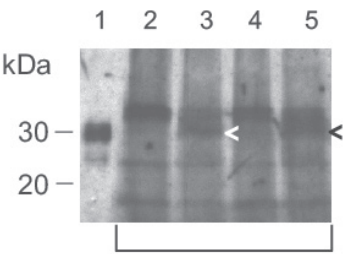

$30 \mathrm{dpi}$

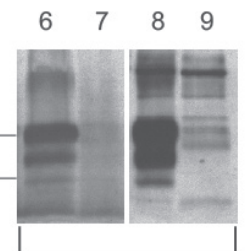

$60 \mathrm{dpi}$

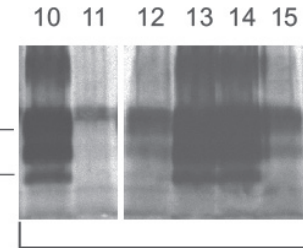

$100 \mathrm{dpi}$
1617

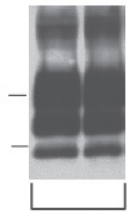

$130 \mathrm{dpi}$

B

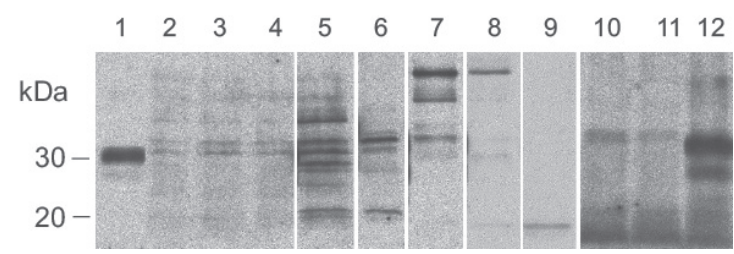

C

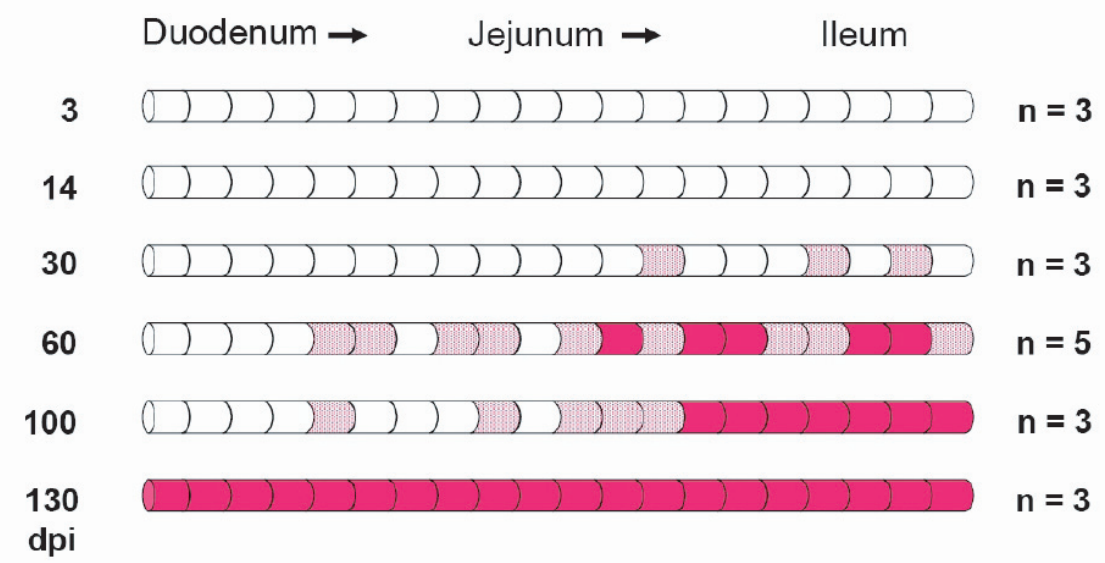

negative $\bigcirc$ positive in a minority $\bigcirc /$ in a majority of animals $\odot$

Figure 3. (A) Western blot detection of PrP27-30, the PK-resistant core of $\operatorname{PrP}^{\mathrm{TSE}}$, in segments of the small intestine from hamsters fed with $263 \mathrm{~K}$ scrapie brain homogenate. Lane 1: Blot control, 263K scrapie hamster brain homogenate containing $1 \times 10^{-7} \mathrm{~g}$ of brain tissue. Lanes 2 to 5: Samples collected at $30 \mathrm{dpi}$ (weak specific immunostaining signals for $\mathrm{PrP}^{\mathrm{TSE}}$ in lanes 3 and 5 are marked by arrowheads). Lanes 6 to 9: Samples collected at $60 \mathrm{dpi}$ (adjacent intestinal samples were blotted in lanes 6 and 7, and in lanes 8 and 9). Lanes 10 to 15: Samples collected at $100 \mathrm{dpi}$ (adjacent intestinal samples were blotted in lanes 10 and 11, and in lanes 12-15; the pattern shown in lanes 12-15 would be compatible with bi-directional spread of infectivity in the wall of the intestinal tract. Lanes 16 and 17: Samples collected 130 dpi. Note: Positive samples at 100 and 130 dpi also show strong staining of PrP27-30 dimers. (B) Range of western-blot signals from different segments of small intestine from uninfected hamsters after $\mathrm{PrP}^{\mathrm{TSE}}$ purification and staining with $\mathrm{mAb} 3 \mathrm{~F} 4$. Lane 1: Blot control, 263K scrapie hamster brain homogenate containing $1 \times 10^{-7} \mathrm{~g}$ of brain tissue. Lanes 2-11: Unspecific immunostaining in extracts from different segments of the small intestine of uninfected hamsters. Lane 12: Positive control; tissue sample collected at $60 \mathrm{dpi}$ from the small intestine of a hamster orally infected with $263 \mathrm{~K}$ scrapie. (C) Initial sites, foci, and spread of PrP ${ }^{T S E}$-deposition in the small intestine of hamsters fed with $263 \mathrm{~K}$ scrapie brain homogenate. Schematic summary of Western blot findings in screened segments of small intestines collected 3, 14, 30, 60, 100 and 130 dpi. $n=$ number of animals investigated.

Page 6 of 17 (page number not for citation purpose) 
brain tissue (Fig. 2B, lanes 22 and 23). The staining intensities of the extracts in lanes 22 and 23 were comparable to that of the reference sample in lane 20 (representing $2 \times 10^{-8} \mathrm{~g}$ of scrapie brain tissue). This indicates that our extraction method recovered in the final extract $\sim 4 \%$ of the faecal $\mathrm{PrP}^{\mathrm{TSE}}$ spike. The staining intensities of extracts from samples spiked with $3 \times 10^{-6} \mathrm{~g}$ of homogenized $263 \mathrm{~K}$ scrapie brain tissue (Fig. 2B, lanes 14-16) resembled those of the reference signals in lanes 13 and 18 (each representing $1 \times 10^{-7} \mathrm{~g}$ of scrapie brain tissue), suggesting an extraction yield of $\sim 3 \%$. Higher amounts of spiking material (i.e. $5 \times 10^{-6} \mathrm{~g}$; Fig. $2 \mathrm{~B}$, lanes 6-8) resulted in slightly increased retrieval rates of $\geq 5 \%$.

\subsubsection{Faecal shedding of PrP $P^{T S E}$}

After feeding scrapie brain homogenate to our model animals, faecal excretion of $\mathrm{PrP}^{\mathrm{TSE}}$ could be observed consistently in samples collected at 24-48 hpi and 48-72 hpi (Fig. 2C, lanes $10-13$ and 14-17, respectively). In contrast, no PrP27-30, the PK-resistant core of $\mathrm{PrP}^{\mathrm{TSE}}$, was detected by Western blotting of extracts from specimens collected at 0-24 hpi (Fig. 2C, lanes 6-9), 72-96 hpi (Fig. 2C, lanes 18-21), or at later preclinical time points that were examined in our study, i.e. at 70, 100, and $130 \mathrm{dpi}$, as well as at the clinical stage of disease (not shown). Thus, the observed retention period of the inoculum in the gastrointestinal tract was found to be $\leq 3$ days. However, PMCA increased the sensitivity of $\operatorname{PrP}^{\mathrm{TSE}}$ detection in faeces and revealed that small amounts of the protein were present in faecal extracts from 2 out of 4 clinically-ill scrapie hamsters that were tested (Fig. 2E). Extracts from normal hamster faeces consistently produced negative results after sPMCA (not shown).

\subsubsection{Fate of ingested $\operatorname{PrP}^{T S E}$}

Hamsters shed between $2-4 \mathrm{~g}$ of faeces per day during the first $96 \mathrm{~h}$ after infection. Together with this observation, a semiquantitative comparison of test- and reference samples in Figures 2C and 2D allowed to assess the proportion of ingested $\operatorname{PrP}^{\mathrm{TSE}}$ that had been faecally excreted. In the following, such an assessment is exemplified for one animal for which the faecal extracts from samples collected at 0-24 hpi, 24-48 hpi, 48-72 hpi and 72-96 hpi have been blotted in lanes $6,10,14$ and 18 of Figure 2C, respectively. For 0-24 hpi and 72-96 hpi no PrP $\mathrm{PSE}^{\mathrm{TS}}$ could be detected. However, the staining intensity observed for 24-48 hpi (Fig. 2C, lane 10) corresponded approximately to that of $1 \times 10^{-6} \mathrm{~g}$ scrapie hamster brain tissue (Fig. 2C, lane 2). Therefore, taking the extraction yield determined above $(\sim 4 \%)$ into account, it can be concluded that the examined faecal sample $(200 \mathrm{mg})$ contained an amount of $\mathrm{PrP}^{\mathrm{TSE}}$ which was equivalent to that present in $2.5 \times 10^{-5} \mathrm{~g}$ of homogenized scrapie hamster brain. For the interval of $48-72 \mathrm{hpi}$ the staining intensity of the faeces sample from the animal (Fig. 2C, lane 14) resembled that of $2.5 \times 10^{-7} \mathrm{~g}$ scrapie hamster brain tissue (Fig. 2C, lane 3), suggesting that the amount of $\mathrm{PrP}^{\mathrm{TSE}}$ in this sample (again $200 \mathrm{mg}$ ) corresponded to that in $6.25 \times 10^{-6} \mathrm{~g}$ scrapie hamster brain tissue. Accordingly, with about $3 \mathrm{~g}$ faeces shed per day, the animal excreted an amount of PrP $\mathrm{PSE}^{\mathrm{TSE}}$ equivalent to that present in approximately $15 \times 2.5 \times 10^{-5} \mathrm{~g}+15 \times$ $6.25 \times 10^{-6} \mathrm{~g}=4.7 \times 10^{-4} \mathrm{~g}$ of scrapie hamster brain tissue, i.e. about $4.7 \%$ of the ingested $\mathrm{PrP}^{\mathrm{TSE}}$. Similar assessments performed for the samples of the three other examined animals displayed in Figure 2C (lanes 7-9, 11-13, 1517 and 19-21), and with further dilutions of faecal extracts as shown in Figure 2D, indicate that on average $5 \%$ of the orally administered $\mathrm{PrP}^{\mathrm{TSE}}$ had been shed via the faeces.

\subsection{Western blot detection of $\operatorname{PrP}^{\mathrm{TSE}}$ in tissue specimens of the gastrointestinal tract}

Western blot examination of gut segments from the small intestine failed to detect PrP $\mathrm{P}^{\mathrm{TSE}}$ at 3 and $14 \mathrm{dpi}$ (Fig. 3C). Initial detection of the protein was achieved at $30 \mathrm{dpi}$ in individual segments of the distal jejunum and ileum in 1 out of 3 animals examined (Figs. 3A and 3C). At 60 dpi, Western blot signals for PrP27-30 
became more prominent and widespread, and isolated foci of deposition were also observed in the border region of the distal duodenum and proximal jejunum (Figs. 3A and 3C). At $100 \mathrm{dpi}$, positive signals in the distal jejunum and ileum showed increasing confluence, and at $130 \mathrm{dpi}$ the entire wall of the small intestine exhibited prominent deposition of $\mathrm{PrP}^{\mathrm{TSE}}$ in the majority of examined animals (Figs. 3A and 3C). First immunoblot detection of focal $\mathrm{PrP}^{\mathrm{TSE}}$ in caudal intestinal regions (caecum, colon) occurred at $100 \mathrm{dpi}$; cranially, initial detectable deposition of $\operatorname{PrP}^{\mathrm{TSE}}$ was found in stomach samples at 130 dpi in 4 hamsters; in 2 out of these 4 animals also the oesophagi were observed to show onset of $\operatorname{PrP}^{\mathrm{TSE}}$ deposition (data not shown).

Extracts from gut specimens of uninfected hamsters showed a variety of unspecific staining signals with $\mathrm{mAb} 3 \mathrm{~F} 4$ in the Western blot (Fig. 3B) which could all be clearly differentiated from PrP27-30. These unspecific signals may have resulted from heterogeneous compounds in the resorptive tissue, depending on the status of the uptake and processing of nutrients, and on differences in the exact tissue composition of the various specimens from the gut wall.

\subsection{Immunohistochemical and PET blot detection of $\operatorname{PrP}^{\mathrm{TSE}}$ in tissue specimens from the distal small intestine}

Since prion invasion of alimentary tract tissue showed its initial manifestation (in terms of the deposition of $\operatorname{PrP}^{\mathrm{TSE}}$ ) in the distal small intestine of our model animals, this gut region was further scrutinized by immunohistochemistry and PET blotting for the detection of $\operatorname{PrP}^{\mathrm{TSE}}$ in GALT and ENS components. Initial foci of $\mathrm{PrP}^{\mathrm{TSE}}$ deposition were detected at $30 \mathrm{dpi}$ (in 5 out of 6 animals, Fig. 4D and Tab. I) and at $45 \mathrm{dpi}$ (in all 6 animals investigated, Figs. 4A-4C and Tab. I) in germinal centers of Peyer's patches. Immunohistochemical observations at 45 dpi (Fig. 4A) could be confirmed by PET blotting of adjacent sections for PrP ${ }^{\mathrm{TSE}}$, which visualized $\mathrm{PrP}^{\mathrm{TSE}}$ by granular, bluemagenta staining (Fig. 4B). In contrast, the
Table I. Immunohistochemical monitoring of PrP $^{\text {TSE }}$ deposition in the GALT and ENS of the distal small intestine from hamsters fed with $263 \mathrm{~K}$ scrapie brain homogenate.

\begin{tabular}{cccccc}
\hline & \multicolumn{5}{c}{ No. of animals tested positive for $\mathrm{PrP}^{\mathrm{TSE}} /$} \\
& \multicolumn{5}{c}{ No. of animals in group } \\
\cline { 2 - 6 } & $3 \mathrm{dpi}$ & $14 \mathrm{dpi}$ & $30 \mathrm{dpi}$ & $45 \mathrm{dpi}$ & $60 \mathrm{dpi}$ \\
\hline GALT & $0 / 2$ & $0 / 6$ & $5 / 6$ & $6 / 6$ & $6 / 6$ \\
ENS & $0 / 2$ & $0 / 6$ & $0 / 6$ & $0 / 6$ & $2 / 6$ \\
\hline
\end{tabular}

ENS did not show deposition of detectable $\mathrm{PrP}^{\mathrm{TSE}}$ at 30 or $45 \mathrm{dpi}$. At $60 \mathrm{dpi} \mathrm{PrP}^{\mathrm{TSE}}$ was found more frequently and widespread in lymphoid follicles in all 6 animals investigated (Figs. 5A-5D and Tab. I) where the protein also often showed co-localisation with macrophages of the dome (Fig. 5D, white arrows). In 1 of the 6 animals showing $\operatorname{PrP}^{\mathrm{TSE}}$ deposition in the GALT at $60 \mathrm{dpi}, \operatorname{PrP}^{\mathrm{TSE}}$ was also detected in association with submucosal nerve-like structures of a lymphoid follicle (Fig. 5C, white arrowheads), and with cells of the follicle associated epithelium (FAE, Fig. 5D, black arrowheads). At the clinical stage of disease the GALT, and particularly Peyer's patches, consistently showed strong immunolabeling for $\operatorname{PrP}^{\mathrm{TSE}}$ in all examined intestinal samples (not shown). ENS ganglia were positive for $\mathrm{PrP}^{\mathrm{TSE}}$ in only 2 out of 6 animals investigated at $60 \mathrm{dpi}$ (Tab. I, Figs. 6A and 6B), but at the terminal stage of scrapie, $\operatorname{PrP}^{\mathrm{TSE}}$ was abundant in submucosal and myenteric plexuses in the small intestine (Fig. 6C). The results obtained in our immunohistochemical examinations from 3 to $60 \mathrm{dpi}$ are summarized in Table I.

\section{DISCUSSION}

\subsection{Intestinal fate of ingested $\operatorname{PrP}^{\mathrm{TSE}}$}

To address the intestinal fate of ingested $\mathrm{PrP}^{\mathrm{TSE}}$, we first examined the shedding of $\mathrm{PrP}^{\mathrm{TSE}}$ in the excrement of orally challenged hamsters around the time-point of infection and the presence of $\operatorname{PrP}^{\mathrm{TSE}}$ in components of the gut wall at 3 and 14 dpi. We consistently detected pathological prion protein in faeces of the animals at $24-48 \mathrm{~h}$ and $48-72 \mathrm{~h}$ after 


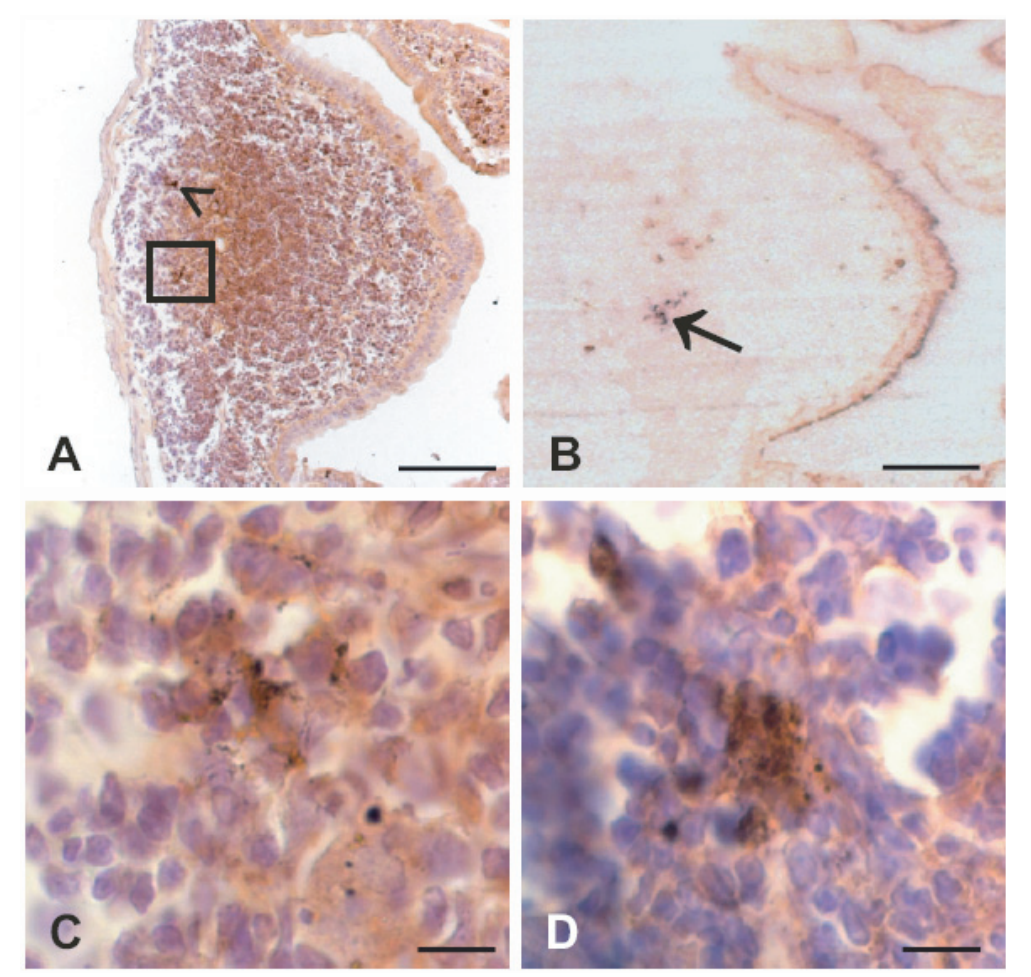

Figure 4. Photomicrographs displaying granularly stained $\operatorname{PrP}^{\mathrm{TSE}}$ detected by immunohistochemical labeling (A, C, D) or PET blotting (B) at 30 or 45 dpi in the GALT of hamsters fed with $263 \mathrm{~K}$ scrapie brain homogenate. $\operatorname{PrP}^{\mathrm{TSE}}$ appears as brown $(\mathrm{A}, \mathrm{C}, \mathrm{D})$ or blue-magenta (B) granular material. (A) Ileal lymphoid follicle at $45 \mathrm{dpi}$ showing $\mathrm{PrP}^{\mathrm{TSE}}$ in the germinal centre (arrowhead and inset in A). (B) PET blot in adjacent section to the specimen displayed in $\mathrm{A}\left(\mathrm{PrP}^{\mathrm{TSE}}\right.$ is indicated by arrow). (C) Higher magnification of inset in A. (D) Detection of PrP ${ }^{\mathrm{TSE}}$ in the germinal center of an ileal lymphoid follicle at 30 dpi. Scale bars in $\mathrm{A}$ and $\mathrm{B}, 40 \mu \mathrm{m}$; in $\mathrm{C}$ and $\mathrm{D}, 5 \mu \mathrm{m}$. (For a colour version of this figure, please consult www.vetres.org.)

peroral uptake of infectious scrapie brain homogenate within the limits of our test sensitivity, but not at 0-24 hpi or later than 72 hpi. Our findings showed that the animals shed on average $5 \%$ of the perorally inoculated $\mathrm{PrP}^{\mathrm{TSE}}$ in the faeces. On the contrary, PrP ${ }^{\mathrm{TSE}}$ could not be detected by Western blotting, PET blotting or immunohistochemistry in specimens of the gut wall at $3 \mathrm{dpi}$ and $14 \mathrm{dpi}$. Thus, a large proportion (i.e. about $95 \%$ ) of the originally inoculated $\operatorname{PrP}^{\mathrm{TSE}}$ apparently disappeared from the intestinal tract.

This clearance seems most likely to have been mediated by degradation, which would be consistent with previous observations by Jeffrey et al. [25] that scrapie-associated
$\operatorname{PrP}^{\mathrm{TSE}}$ is readily digested by fluids of the alimentary tract from sheep. Resorption and conveyance to extra-intestinal sites such as peripheral lymph nodes [21] or other LRS components could provide an alternative explanation for the observed $\mathrm{PrP}^{\mathrm{TSE}}$ clearance. However, in our model animals drainage of inoculum to LRS components outside the gut may be of lower importance for the intestinal clearance than degradation, since infectivity and $\mathrm{PrP}^{\mathrm{TSE}}$ were found only relatively late (i.e. subsequently to invasion of the brain and spinal cord) in the spleen of hamsters orally challenged with scrapie [5]. Apart from the shed or cleared proportions of the ingested $\mathrm{PrP}^{\mathrm{TSE}}$, an indiscernible fraction of 


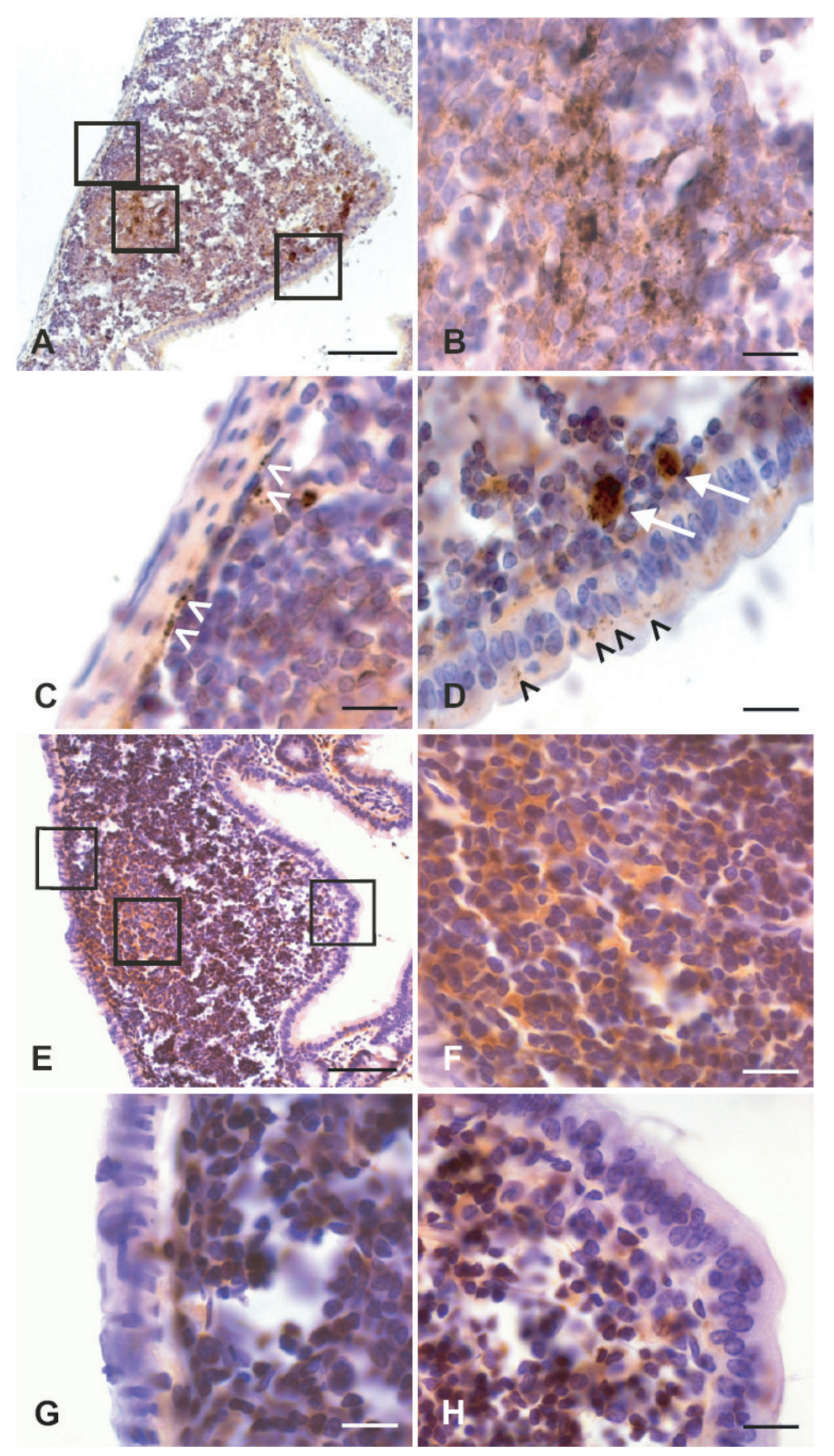

Figure 5. Photomicrographs displaying $\operatorname{Pr}^{\mathrm{TSE}}$ detected by immunohistochemical staining at $60 \mathrm{dpi}$ in the GALT of a hamster fed with $263 \mathrm{~K}$ scrapie brain homogenate (A-D). Lymphoid follicle from the distal jejunum showing granular deposits of $\operatorname{PrP}^{\mathrm{TSE}}$ in the germinal center $(\mathrm{A}$, middle inset; $\mathrm{B}$, higher magnification of middle inset in A), in submucosal nerve-like structures (A, left inset; $\mathrm{C}$, higher magnification of left inset in $\mathrm{A}$, white arrowheads), in cells of the FAE and in macrophages of the dome (A, right inset; $\mathrm{D}$, higher

Page 10 of 17 (page number not for citation purpose) 
the perorally administered inoculum triggered intestinal infection as evidenced by progressing $\mathrm{PrP}^{\mathrm{TSE}}$ accumulation in components of the gut wall.

\subsection{Course of $\operatorname{PrP}^{\mathrm{TSE}}$ deposition in the GALT and ENS}

In order to identify the regions of initial $\operatorname{PrP}^{\mathrm{TSE}}$ deposition in the gastrointestinal tract of orally challenged hamsters we screened samples from the oesophagus, stomach, small intestine, caecum and large intestine by Western blotting. This revealed the distal jejunum and ileum as the most prominent sites containing initial foci of $\operatorname{PrP}^{\mathrm{TSE}}$ deposition. Such foci, which were observable at $30 \mathrm{dpi}$ in our model animals, probably did not represent the original inocula (since no $\mathrm{PrP}^{\mathrm{TSE}}$ could be detected by Western blotting at 3 and $14 \mathrm{dpi}$ ) but most plausibly resulted from replication of the agent at sites of primary infection. In contrast, detectable $\mathrm{PrP}^{\mathrm{TSE}}$ deposition in tested segments from the large intestine, stomach or oesophagus was found to start significantly later, i.e. between 100 and $130 \mathrm{dpi}$. This was rather indicative of secondary infection that may have occurred by spread within the wall of the alimentary tract or from other parts of the body.

In the distal small intestine, primary infection of tissue with ingested inoculum may have been particularly facilitated by the relatively abundant presence of Peyer's patches [17], and by an increased contact of infectious inoculum with the luminal surface of the intestinal wall due to a physiologically delayed ileal transit time [20]. Peyer's patches of the caudal jejunum and ileum were also described to accumulate $\operatorname{PrP}^{\mathrm{TSE}}$ early in the pathogenesis of natural sheep scrapie $[2,51]$.
Similarly, in BSE-infected cattle, where the presence of infectious agent is essentially confined to the brain, spinal cord and retina [12], the BSE agent was detected in the distal ileum during preclinical and clinical phases of incubation after experimental peroral challenge [19, 53, 54].

According to the results of our Western blot study, and building on the course of infection in the GALT and ENS of perorally infected hamsters that had been established in previous studies for the period of time between $69 \mathrm{dpi}$ and terminal disease [7,33], we focused on the distal small intestine to further probe the early $\operatorname{PrP}^{\mathrm{TSE}}$ deposition in the gut wall by immunohistochemistry and PET blotting at 3, 14, 30, 45 and 60 dpi. For our immunohistochemical analysis, only staining signals of clearly recognizable granular deposits (but not homogeneous brown immunolabeling) were considered as indicative of $\operatorname{PrP}^{\mathrm{TSE}}$ [6].

Our examinations provided negative results at 3 and $14 \mathrm{dpi}$, but demonstrated the presence of $\mathrm{PrP}^{\mathrm{TSE}}$ in Peyer's patches of the GALT in the majority of animals at 30 and $45 \mathrm{dpi}$ (Tab. I). At 30 dpi the immunohistochemical staining for $\mathrm{PrP}^{\mathrm{TSE}}$ was often restricted to only one or two $6 \mu \mathrm{m}$ sections, indicating that a rather limited number of follicular dendritic cells (FDC) was involved in the detected initial deposition of the protein. At 60 dpi IHC revealed the presence of $\operatorname{PrP}^{\mathrm{TSE}}$ not only in the FDC network but also associated with membranous epithelial cells (possibly $\mathrm{M}$ cells) of the FAE [7], macrophages of the dome und submucosal nerve-like structures (Figs. 5C and 5D). In contrast to the GALT, the onset of $\operatorname{PrP}^{\mathrm{TSE}}$ deposition in ENS components such as myenteric plexuses were found not earlier than 60 dpi (Tab. I, Figs. 6A and 6B).

Figure 5 (continued). magnification of right inset in A, black arrowheads and white arrows, respectively). Scale bars in A, $40 \mu \mathrm{m}$; in B, C and D, $5 \mu \mathrm{m}$. Photomicrographs of a lymphoid follicle from the distal ileum of an uninfected hamster labeled immunohistochemically with mAb 3F4 (E-G). Unspecific homogeneous brown staining in the germinal center (E, middle inset; $\mathrm{F}$, higher magnification of middle inset in $\mathrm{E}$ ). Granular immunostaining for $\operatorname{PrP}^{\mathrm{Sc}}$ deposits is absent in the submucosal region (E, left inset; $\mathrm{G}$, higher magnification of left inset in $\mathrm{E}$ ), or in the FAE (E, right inset; $\mathrm{H}$, higher magnification of right inset in $\mathrm{E}$ ). Scale bars in E, $40 \mu \mathrm{m}$; in F, G and H, $5 \mu \mathrm{m}$. (For a colour version of this figure, please consult www.vetres.org.) 

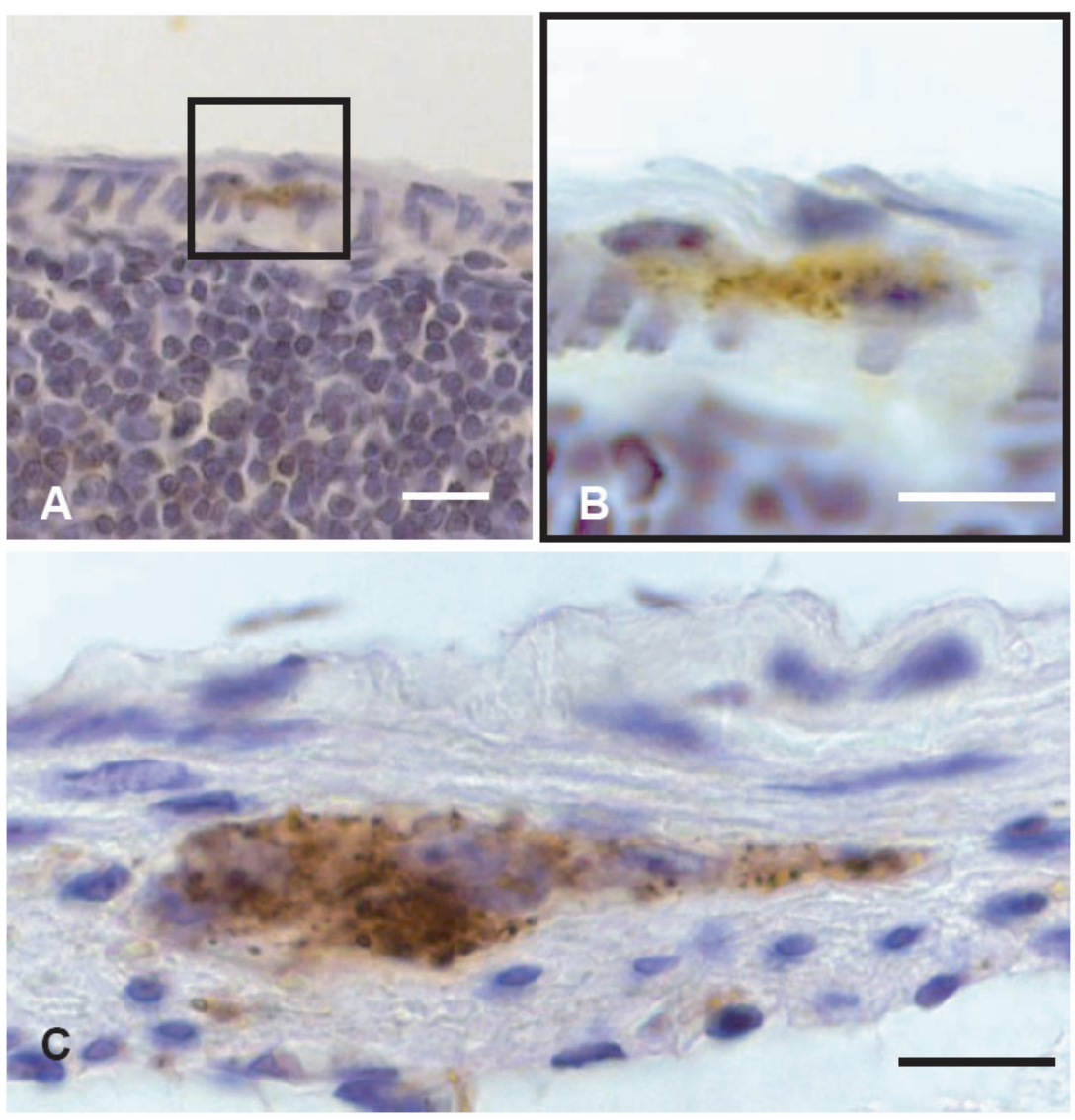

Figure 6. Photomicrographs displaying $\operatorname{PrP}^{\mathrm{TSE}}$ detected by immunohistochemical staining at $60 \mathrm{dpi}(\mathrm{A}$, B) and at the clinical stage of scrapie $(160 \mathrm{dpi}, \mathrm{C})$ in myenteric ganglia of the ileal ENS of hamsters fed with $263 \mathrm{~K}$ scrapie brain homogenate. Scale bars $5 \mu \mathrm{m}$. (For a colour version of this figure, please consult www.vetres.org.)

At the terminal stage of scrapie, $\operatorname{PrP}^{\mathrm{TSE}}$ was consistently present in both GALT and ENS, as has already been established in previous studies that found progressing accumulation of $\mathrm{PrP}^{\mathrm{TSE}}$ in these intestinal tissues of hamsters orally challenged with scrapie from $69 \mathrm{dpi}$ (the earliest time point available) until clinical disease $[7,8,33]$.

Recently, Bergström et al. [9] reported immunohistochemical detection of $\operatorname{PrP}^{\mathrm{TSE}}$ in Peyer's patches already 2, 4 and 8 days after oral infection of hamsters with $263 \mathrm{~K}$ scrapie agent. In this study, a tenfold higher dose of agent than that used by us was administered to the animals which may account for the difference in the time points for the initial detection of GALT-related $\mathrm{PrP}^{\mathrm{TSE}}$ found by these authors and us. Bergström et al. [9] concluded that "Peyer's patches constitute at least one of the primary entry sites of $\mathrm{PrP}^{\mathrm{Sc}}$ after oral exposure to scrapie". By examination of the ENS additionally to the GALT, our study sheds further light on the sequence of $\mathrm{PrP}^{\mathrm{TSE}}$ deposition in these intestinal tissue components. The findings described above show that at intestinal sites of putatively primary infection the onset of detectable $\mathrm{PrP}^{\mathrm{TSE}}$ deposition in lymphoid 
tissue clearly preceded that in submucosal or myenteric ganglia. If the observed temporalspatial pattern of $\mathrm{PrP}^{\mathrm{TSE}}$ deposition in the examined intestinal tissue samples correctly reflects the spread of infection, this would be indicative of the GALT being involved in both, establishment of primary intestinal infection and propagation of infection to the ENS in our model animals. Whether blood or lymph is involved in the spread of infection to the ENS has not yet been elucidated and would require further examination.

Findings in other murine models suggest that neuroinvasion can also occur in the absence of detectable lymphoid infection, e.g. after oral challenge by a high dose of agent or exposure to highly neuroinvasive TSE strains [8]. Furthermore, although comprehensive studies in Texel sheep naturally infected with scrapie [50] suggested that the proximity of Peyer's patches and plexuses of the ENS may facilitate neuroinvasion, in sheep carrying the genotype $\operatorname{Pr} \mathrm{P}^{\mathrm{VRQ} / \mathrm{ARR}} \mathrm{CNS}$ invasion is reported to occur without preceding infection of lymphoid tissue [51]. Also, a subset of sheep orally infected with BSE showed invasion of the CNS without detectable $\operatorname{PrP}^{\mathrm{TSE}}$ in the lymphoid system [24]. Thus, it has to be noted that the intestinal routing of prions after ingestion of infectivity may considerably vary depending on the combination of the prion strain, dose of the agent and host species.

\subsection{Shedding of endogenously formed $\operatorname{PrP}^{\mathrm{TSE}}$ in faeces}

The deposition of substantial amounts of $\operatorname{PrP}^{\mathrm{TSE}}$, particularly associated with Peyer's patches, in close vicinity to the lumen of the small intestine found here and in other studies both before and after the onset of clinical symptoms $[9,49,53]$ is suggestive of a further role of the GALT in the pathogenesis after oral scrapie infection. This role would be to provide a source for dissemination of replicated prions from the gut wall into faeces. We found $\mathrm{PrP}^{\mathrm{TSE}}$ in membranous epithelial cells of the FAE directly adjacent to the intestinal lumen, and release of viruses from the apical (or luminal) surface of polarized intestinal epithelial cells has been described in a variety of reports $[14,48]$. Deposition of $\mathrm{PrP}^{\mathrm{TSE}}$ in FAE components has been observed already previously in orally infected hamsters [7] and in BSE-infected lemurs [10]. However, so far, FAE components such as $\mathrm{M}$ cells are discussed primarily as candidate sites of prion entry into the gut wall $[7,18]$. Our findings point to a second or alternative role of the FAE in the pathogenesis of orally acquired scrapie and indicate that the FAE may serve as a site for prion release from the host. Theoretically, such dissemination may also arise from other intestinal tissues such as infected ENS, but with respect to their load of $\mathrm{PrP}^{\mathrm{TSE}}$ and anatomical location Peyer's patches would appear as the prime candidate source of intestinal prion release.

However, after the initial shedding observed at 24-72 hpi we first failed to detect $\mathrm{PrP}^{\mathrm{TSE}}$ by Western blotting of faecal extracts at any time point tested during the preclinical or clinical stage of infection. Our analytical extraction procedure, which recovered $\sim 4 \%$ of the faecal $\operatorname{PrP}^{\mathrm{TSE}}$ spike in the final extract, was able to detect $\operatorname{PrP}^{\mathrm{TSE}}$ when an amount of $5 \times 10^{-7} \mathrm{~g}$ of scrapie hamster brain, i.e. $\sim 50 \mathrm{pg}$ of $\mathrm{PrP}^{\mathrm{TSE}}$ [5], was added to $200 \mathrm{mg}$ of faeces and an extract representing $200 \mathrm{mg}$ of spiked faeces was loaded onto the gel for Western blotting. As known from previous titrations $[3,5]$, such spikes contained about $0.5-1.5 \times 10^{3}$ intracerebral (i.c.) infective doses (LD50 i.c.). Accordingly, unknown faecal samples (of which extracts representing $200 \mathrm{mg}$ of starting material were loaded for Western blotting) should have produced positive results if they had contained an amount of $\mathrm{PrP}^{\mathrm{TSE}}$ corresponding to $\geq 5 \times 10^{-7} \mathrm{~g}$ of scrapie hamster brain per $200 \mathrm{mg}$ of faeces (i.e. $\geq 2.5 \times 10^{-6} \mathrm{~g}$ of scrapie hamster brain per $1 \mathrm{~g}$ of faeces). When the exogenous spiking material is representative of endogenous $\mathrm{PrP}^{\mathrm{TSE}}$ in faeces, our observations suggest that the concentration of $\mathrm{PrP}^{\mathrm{TSE}}$ in faeces from negatively tested donors was at least 400000 -fold lower than that in the brain. If, furthermore, in faeces $\mathrm{PrP}^{\mathrm{TSE}}$ correlates with infectivity in a similar 
ratio to that observed previously in the CNS $[3,5]$, this would indicate that infectivity in the faeces, if present, would be lower than 2.5 to $7.5 \times 10^{3} \mathrm{LD}_{50}$ per gram.

In order to examine whether excretion of $\mathrm{PrP}^{\mathrm{TSE}}$ by shedding from infected Peyer's patches (as also recently suggested by Safar et al. [39]) or other contaminated components of the gut wall occurred at low levels not detectable by direct Western blotting when intestinal $\mathrm{PrP}^{\mathrm{TSE}}$ deposition had been established, we performed serial PMCA of faecal extracts from clinically-ill scrapie hamsters. This revealed the presence of small amounts of $\operatorname{PrP}^{\mathrm{TSE}}$ that eluded detection when such extracts were analysed without in vitro amplification of the pathological prion protein. Excrement may thus also provide a vehicle for the release of endogenously formed $\mathrm{PrP}^{\mathrm{TSE}}$. In the light of the data available so far, this release seems to occur predominantly from Peyer's patches, possibly under involvement of the FAE. However, the rather low level of contamination found in faeces from clinicallyill animals suggests that such a mode of prion dissemination is at least partially counteracted by the observed ability of the digestive tract to clear substantial amounts of $\mathrm{PrP}^{\mathrm{TSE}}$ from the alimentary canal.

\subsection{Previous reports on the excretion and detection of prions in faeces}

A recent study on the excretion of scrapie and BSE-associated $\mathrm{PrP}^{\mathrm{TSE}}$ in stools of intragastrically challenged mice [29] reported remarkably similar results to our observations with respect to the shedding kinetics of $\mathrm{PrP}^{\mathrm{TSE}}$ around the time-point of infection, despite differences in the route of inoculation, dose and strain of the agent, and host species. This may be indicative of common characteristics in the alimentary processing of ingested $\mathrm{PrP}^{\mathrm{TSE}}$. However, the mouse study did not address the intestinal fate of ingested $\mathrm{PrP}^{\mathrm{TSE}}$ in detail and failed to detect the protein in samples from mice clinically affected with scrapie.

Safar et al. [39] recently addressed the transmission and detection of prions in faeces from hamsters orally challenged with Sc237 scrapie agent (presumably identical to $263 \mathrm{~K}$ scrapie). These authors found that faecal shedding of $\mathrm{PrP}^{\mathrm{TSE}}$, as determined by conformation dependent immunoassay (CDI), peaked at 2 days after infection and then gradually decreased for the next 16 days. From 20 dpi until the onset of scrapie symptoms, the CDI detected fluctuating levels of PrP ${ }^{\mathrm{TSE}}$ in the excrement. The highest infectivity levels in faeces, as determined by bioassay, were detected at 2 and $8 \mathrm{dpi}$, and excretion of prions then continued at lower levels throughout the entire asymptomatic phase of incubation. The pronounced faecal shedding of PrP $\mathrm{P}^{\mathrm{TSE}}$ and infectious prions observed by Safar et al. [39] may have resulted from the very high dose of agent perorally administered in this experiment (the animals were fed one-half of a scrapie hamster brain which corresponds to about $500 \mathrm{mg}$ of brain tissue). Such a dose possibly "overwhelmed" the digestive system [11] and compromised its ability to clear PrP $\mathrm{P}^{\mathrm{TSE}}$ as efficiently from the alimentary tract as observed when hamsters were fed a lower amount (i.e. $10 \mathrm{mg}$ ) of scrapie brain homogenate.

Using different doses for peroral infection, the study by Safar et al. and our work produced complementary findings. By administering a relatively low dose of agent, we were able to elucidate the fate of the ingested $\operatorname{PrP}^{\mathrm{TSE}}$ in more detail. Furthermore, our immunohistochemical and PET blot examinations of the gut wall experimentally substantiated the notion discussed by Safar et al. [39] that contamination of faeces with prions may be mediated by shedding from infected Peyer's patches.

\subsection{The possible role of faeces in the transmission of contagious prion diseases}

With respect to previously raised assumptions that contaminated excrements may be involved in the horizontal transmission of natural sheep scrapie in endemically affected flocks [2], several different aspects have to be considered: First, ruminants have a specific LRS component at the recto-anal junction, (sometimes referred to as "RAMALT") which 
accumulates $\operatorname{PrP}^{\mathrm{TSE}}$, and from where possibly contaminated macrophages may be released into the very distal gut lumen [16] and shed into the environment. Second, ruminants shed relatively large quantities of faeces, and binding of prions to soil may substantially enhance the efficiency of peroral scrapie transmission [26]. Third, specific factors could possibly enhance dissemination of $\operatorname{PrP}^{\mathrm{TSE}}$ from the gut wall. This holds particularly true for injuries that may lead to the shedding of intestinal tissue debris, parasiticor other co-infections $[23,35]$, and inflammatory processes [42]. Apart from faeces, other vehicles have been discussed for TSE transmissions in the field, e.g. contaminated placenta, decomposed carcasses, saliva, urine or skin $[15,30,34,38,42,46]$. Our protocol for the detection of $\mathrm{PrP}^{\mathrm{TSE}}$ in faeces combined with sPMCA can help to test excrements from ovines, caprines or cervids in future studies to further pinpoint the sources of infection in contagious prion diseases of animals.

Acknowledgements. We thank Marion Joncic, Ramona Famulla, Patrizia Reckwald and Manuela Friedrich for excellent technical assistance. This work was supported by the EU-funded Network of Excellence "NeuroPrion", the Deutsche Forschungsgemeinschaft (DFG, TH 1376/2-1) and the German Bundesministerium für Bildung und Forschung (BMBF, FKZ 01KO0515). Dominique Krüger dedicates this article to his mentor, the nutritionist and Director and Professor Rolf Grossklaus.

\section{REFERENCES}

[1] Aguzzi A., Polymenidou M., Mammalian prion biology: one century of evolving concepts, Cell (2004) 116:313-327.

[2] Andréoletti O., Berthon P., Marc D., Sarradin P., Grosclaude J., Van Keulen L., et al., Early accumulation of $\operatorname{PrP}^{\mathrm{TSE}}$ in gut-associated lymphoid and nervous tissues of susceptible sheep from a Romanov flock with natural scrapie, J. Gen. Virol (2000) 81:3115-3126.

[3] Baldauf E., Beekes M., Diringer H., Evidence for an alternative direct route of access for the scrapie agent to the brain bypassing the spinal cord, J. Gen. Virol. (1997) 78:1187-1197.

[4] Beekes M., Baldauf E., Caßens S., Diringer H., Keyes P., Scott A.C., et al., Western blot mapping of disease-specific amyloid in various animal species and humans with transmissible spongiform encephalopathies using a high-yield purification method, J. Gen. Virol. (1995) 76:2567-2576.

[5] Beekes M., Baldauf E., Diringer H., Sequential appearance and accumulation of pathognomonic markers in the central nervous system of hamsters orally infected with scrapie, J. Gen. Virol. (1996) 77:1925-1934.

[6] Beekes M., McBride P.A., Baldauf E., Cerebral targeting indicates vagal spread of infection in hamsters fed with scrapie, J. Gen. Virol. (1998) 79:601-607.

[7] Beekes M., McBride P.A., Early accumulation of pathological PrP in the enteric nervous system and gutassociated lymphoid tissue of hamsters orally infected with scrapie, Neurosci. Lett. (2000) 278:181-184.

[8] Beekes M., McBride P.A., The spread of prions through the body in naturally acquired transmissible spongiform encephalopathies, FEBS J. (2007) 274:588-605.

[9] Bergström A.-L., Jensen T.K., Heegaard P.M.H., Cordes H., Hansen V.B., Laursen H., Lind P., Shortterm study of the uptake of $\operatorname{PrP}^{\mathrm{TSE}}$ by the Peyer's patches in hamsters after oral exposure to scrapie, J. Comp. Pathol. (2006) 134:126-133.

[10] Bons N., Mestre-Frances N., Belli P., Cathala F., Gajdusek D.C., Brown P., Natural and experimental oral infection of nonhuman primates by bovine spongiform encephalopathy agents, Proc. Natl. Acad. Sci. USA (1999) 96:4046-4051.

[11] Bosque P.J., Tyler K.L., Prions' travels - feces and transmission of prion diseases, J. Infect. Dis. (2008) 198:8-9.

[12] Bradley R., Bovine spongiform encephalopathy and its relationship to the variant form of CreutzfeldtJakob disease, Contrib. Microbiol. (2004)11:146-185.

[13] Brown P., Cervenakova L., A prion lexicon (out of control), Lancet (2005) 365:122.

[14] Compans R.W., Virus entry and release in polarized epithelial cells, Curr. Top. Microbiol. Immunol. (1995) 202:209-219.

[15] DeJoia C., Moreaux B., O'Connell K., Bessen R.A., Prion infection of oral and nasal mucosa, J. Virol. (2006) 80:4546-4556.

[16] Gonzales L., Jeffrey M., Siso S., Martin S., Bellworthy S., Stack M.J., et al., Diagnosis of preclinical scrapie in samples of rectal mucosa, Vet. Rec. (2005) 156:846-847.

[17] Griebel P.J., Hein W.R., Expanding the role of Peyer's patches in B-cell ontogeny, Immunol. Today (1996) 17:30-39.

(page number not for citation purpose) Page 15 of 17 
[18] Heppner F.L., Christ A.D., Klein M.A., Prinz M., Fried M., Kraehenbuhl J.-P., Aguzzi A., Transepithelial prion transport by $\mathrm{M}$ cells, Nat. Med. (2001) 7:976-977.

[19] Hoffmann C., Ziegler U., Buschmann A., Weber A., Kupfer L., Oelschlegel A., et al., Prions spread via the autonomic nervous system from the gut to the central nervous system in cattle incubating bovine spongiform encephalopathy, J. Gen. Virol. (2007) 88:1048-1055.

[20] Holgate A.M., Read N.W., Relationship between small bowel transit time and absorption of a solid meal, Dig. Dis. Sci. (1983) 28:812-819.

[21] Huang F.-P., Farquhar C.F., Mabbot N.A., Bruce M.E., MacPherson G.G., Migrating intestinal dendritic cells transport $\mathrm{PrP}^{\mathrm{TSE}}$ from the gut, J. Gen. Virol. (2002) 83:267-271.

[22] Ironside J.W., McCardle L., Horsburgh A., Lim Z., Head M.W., Pathological diagnosis of variant Creutzfeldt-Jakob disease, APMIS (2002) 110:79-87.

[23] Jeffrey M., Martin S., Thomson J.R., Dingwall W.S., Begara-McGorum I., Gonzáles L., Onset and distribution of tissue prp accumulation in scrapieaffected suffolk sheep as demonstrated by sequential necropsies and tonsillar biopsies, J. Comp. Pathol. (2001) 125:48-57.

[24] Jeffrey M., Ryder S., Martin S., Hawkins S.A., Terry L., Berthelin-Baker C., Bellworthy S.J., Oral inoculation of sheep with the agent of bovine spongiform encephalopathy (BSE). 1. Onset and distribution of disease-specific PrP Accumulation in brain and viscera. J. Comp. Pathol. (2001) 124:280289.

[25] Jeffrey M., González L., Espenes A., Press C.M., Martin S., Chaplin M., et al., Transportation of prion protein across the intestinal mucosa of scrapiesusceptible and scrapie-resistant sheep, J. Pathol. (2006) 209:4-14.

[26] Johnson C.J., Phillips K.E., Schramm P.T., McKenzie D., Aiken J.M., Joel A., Pedersen J.A., Prions adhere to soil minerals and remain infectious, PloS Pathog. (2006) 2:e32

[27] Kascsak R.J., Rubenstein R., Merz P.A., Tonna-Demasi M., Fersko R., Carp R.I., et al., Mouse polyclonal and monoclonal anibody to scrapie-associated fibril protein, J. Virol. (1987) 61:3688-3693.

[28] Mabbott N.A., MacPherson G.G., Prions and their lethal journey to the brain, Nat. Rev. Microbiol. (2006) 4:201-211.

[29] Maluquer de Motes C., Grassi J., Simon S., Herva M.E., Torres J.M., Pumarola M., Girones R., Excretion of BSE and scrapie prions in stools from murine models, Vet. Microbiol. (2008) 131:205-211.

[30] Mathiason C.K., Powers J.G., Dahmes S.J., Osborn D.A., Miller K.V., Warren R.J., et al., Infectious prions in the saliva and blood of deer with chronic wasting disease, Science (2006) 314:133-136.

[31] McBride P.A., Wilson M.I., Eikelenboom P., Tunstall A., Bruce M.E., Heparan sulfate proteoglycan is associated with amyloid plaques and neuroanatomically targeted PrP pathology throughout the incubation period of scrapie-infected mice, Exp. Neurol. (1998) 149:447-454.

[32] McBride P.A., Beekes M., Pathological PrP is abundant in sympathetic and sensory ganglia of hamsters fed with scrapie, Neurosci. Lett. (1999) 265:135-138.

[33] McBride P.A., Schultz-Schaeffer W.J., Donaldson M., Bruce M., Diringer H., Kretzschmar H.A., Beekes M., Early spread of scrapie from the gastrointestinal tract to the central nervous system involves autonomic fibers of the splanchnic and vagus nerves, J. Virol. (2001) 75:9320-9327.

[34] Miller M.W., Williams E.S., Hobbs N.T., Wolfe L.L., Environmental sources of prion transmission in mule deer, Emerg. Infect. Dis. (2004) 10: 1003-1006.

[35] O’Donoghue P.J., Cryptosporidium and cryptosporidiosis in man and animals, Int. J. Parasitol. (1995) 25:139-195.

[36] Prusiner S.B., Novel proteinaceous infectious particles cause scrapie, Science (1982) 216:136144.

[37] Prusiner S.B., Prions, Proc. Natl. Acad. Sci. USA (1998) 95:13363-13383.

[38] Race R., Jenny A., Sutton D., Scrapie infectivity and proteinase K-resistant prion protein in sheep placenta, brain, spleen, and lymph node: implications for transmission and antemortem diagnosis, J. Infect. Dis. (1998) 178:949-953.

[39] Safar J.G., Lessard P., Tamgüney G., Freyman Y., Deering C., Letessier F., DeArmond S.J., Prusiner S.B., Transmission and detection of prions in feces, J. Infect. Dis. (2008) 198:81-89.

[40] Schaller O., Fatzer R., Stack M., Clark J., Cooley W., Biffiger K., et al., Validation of a western immunoblotting procedure for bovine $\operatorname{PrP}(\mathrm{Sc})$ detection and its use as a rapid surveillance method for the diagnosis of bovine spongiform encephalopathy (BSE), Acta Neuropathol. (1999) 98:437-443.

[41] Schulz-Schaeffer W., Tschöke S., Kranefuss N., Dröse W., Hause-Reitner D., Giese A., et al., The paraffin-embedded tissue blot detects $\operatorname{PrP}(\mathrm{Sc})$ early in 
the incubation time in prion diseases, Am. J. Pathol. (2000) $156: 51-56$.

[42] Seeger H., Heikenwälder M., Zeller N., Kranich J., Schwarz P., Gaspert A., et al., Coincident scrapie infection and nephritis lead to urinary prion excretion, Science (2005) 310:324-326.

[43] Seidel B., Thomzig A., Buschmann A., Groschup M.H., Peters R., Beekes M., Terytze K., Scrapie agent (strain 263K) can transmit disease via the oral route after persistence in soil over years, PLoS ONE (2007) 2:e435.

[44] Thomzig A., Kratzel C., Lenz G., Krüger D., Beekes M., Widespread $\operatorname{PrP}^{\mathrm{TSE}}$ accumulation in muscles of hamsters orally infected with scrapie, EMBO Rep. (2003) 4:530-533.

[45] Thomzig A., Schulz-Schaeffer W., Kratzel C., Mai J., Beekes M., Preclinical deposition of pathological prion protein $\operatorname{PrP}^{\mathrm{TSE}}$ in muscles of hamsters orally exposed to scrapie, J. Clin. Invest. (2004) 113:14651472

[46] Thomzig A., Schulz-Schaeffer W., Wrede A., Wemheuer W., Brenig B., Kratzel C., et al., Accumulation of pathological prion protein $\mathrm{PrP} \mathrm{P}^{\mathrm{TSE}}$ in the skin of animals with experimental and natural scrapie, PLoS Pathog. (2007) 3:659-667.

[47] Thuring C.M., van Keulen L.J., Langeveld J.P., Vromans M.E., van Zijderveld F.G., Sweeney T., Immunohistochemical distinction between preclinical bovine spongiform encephalopathy and scrapie infection in sheep, J. Comp. Pathol. (2005) 132:59-69.
[48] Tucker S.P., Thornton C.L., Wimmer E., Compans R.W., Vectorial release of poliovirus from polarized human intestinal epithelial cells, J. Virol. (1993) 67:4274-4282.

[49] Van Keulen L.J.M., Schreuder B.E.C., Vromans M.E.W., Langeveld J.P.M., Smits M.A., Scrapieassociated prion protein in the gastrointestinal tract of sheep with natural scrapie, J. Comp. Pathol. (1999) 121:55-63.

[50] Van Keulen L.J.M., Schreuder B.E.C., Vromans M.E.W., Langeveld J.P.M., Smits M.A., Pathogenesis of natural scrapie in sheep, Arch. Virol. Suppl. (2000) 16:57-71.

[51] Van Keulen L.J.M., Vromans M.E.W., van Zijderveld F.G., Early and late pathogenesis of natural scrapie infection in sheep, APMIS (2002) 110: 23-32.

[52] Wadsworth J.D., Joiner S., Hill A.F., Campbell T.A., Desbruslais M., Luthert P.J., Collinge J., Tissue distribution of protease resistant prion protein in variant Creutzfeldt-Jakob disease using a highly sensitive immunoblotting assay, Lancet (2001) 358:171-180.

[53] Wells G.A., Dawson M., Hawkins S.A., Green R.B., Dexter I., Francis M.E., et al., Infectivity in the ileum of cattle challanged orally with bovine spongiform encephalopathy, Vet. Rec. (1994) 135:4041.

[54] Wells G.A., Hawkins S.A., Green R.B., Austin A.R., Dexter I., Spencer Y.I., et al., Preliminary observations on the pathogenesis of experimental bovine spongiform encephalopathy (BSE): an update, Vet. Rec. (1998) 142:103-106. 